UDC 539.67:539.374

\title{
THE STUDY OF THE INFLUENCE OF X-RAY IRRADIATION ON DISLOCATION CHARACTERISTICS IN LiF CRYSTALS
}

\author{
O.M. Petchenko, G.O. Petchenko, S.M. Boiko, A.S. Litvinenko \\ O.M. Beketov National University of Urban Economy in Kharkiv, Kharkiv, Ukraine \\ E-mail: gdaeron@ukr.net
}

The dependences of the absorption $\alpha$ and the ultrasound velocity in LiF single crystals with residual deformation $\varepsilon=0.65 \%$ at $300 \mathrm{~K}$ in the range of radiation doses $0 \ldots 1057 \mathrm{R}$ were studied using the acoustic pulse echo method at a frequency of $7.5 \mathrm{MHz}$. Based on the results of measurements of the acoustic characteristics, the absolute values of the parameters of the dislocation structure - the average effective length of the dislocation loop $L$ and the dislocation density $\Lambda$ and their dependences on the irradiation time are determined. The calculated characteristics are compared with the previously obtained results for the high-frequency branch of the damped dislocation resonance and using the selective etching method. The revealed noticeable discrepancy in the values of these parameters is explained by the impossibility of describing a single attenuation mechanism for acoustic measurements carried out in a wide frequency range.

\section{INTRODUCTION}

It can be seen from reviews [1-8] that a lot of theoretical and experimental works have been devoted to the study of the effect of radiation exposure on the properties of crystals. It became known that an increase in the number of radiation centers in ionic crystals stimulates the appearance of acoustic effects caused by the interaction of the indicated point defects with easily mobile dislocations. Low-frequency methods of amplitudedependent internal friction proved to be the most effective for registering the beginning of the process of settling on dislocations of various stoppers $[1,2]$. With their help, it is possible to clearly record the most insignificant changes in the average effective length of the dislocation loop $L$ which oscillates in the field of an ultrasonic wave. These changes, by virtue of the law $\alpha \sim L^{4}$ [3], have a very significant effect on the value of the measured attenuation $\alpha$ of ultrasound in the sample. These methods are very sensitive to the appearance of radiation centers in the crystal, although their application is fraught with certain difficulties. First, when a low-frequency wave of large amplitude is transmitted in the crystal under study, deformation can occur by the ultrasound itself, which can lead to a change in both the quantity both the quantities $L$ and the dislocation density $\Lambda$. In addition, at large amplitudes of the ultrasonic wave, small portions of radiation defects cannot exhibit a noticeable pinning effect on a moving dislocation. Therefore, in low-frequency experiments, large doses of radiation are often used, which can lead to changes in the mechanical [1, 5-7] and optical [8-17] characteristics of crystals.

In this regard, to solve such problems, it began to use the amplitude-independent, acoustic method of megahertz frequency range [18-27], which is highly informative and highly sensitive to the effect of weak radiation stoppers on the dislocation. Analyzing a large array of experimental data $[1,4-8,18,20-27]$ on the dynamics of dislocations under various external influences, one can see that only the results obtained from the descending branch of the damped dislocation reso- nance are quite correct. The results obtained from the data for the low-frequency branch of the indicated resonance require serious verification and refinement.

Thus, the purpose of this paper is to determine the absolute values of the parameters of the dislocation structure $L, \Lambda$ and their dependences on the irradiation time from the data of low-frequency measurements and to compare them with similar results obtained for the resonance region and the descending branch of the frequency dependence of the damping decrement ultrasound.

\section{MATERIALS}

\section{AND EXPERIMENTAL TECHNIQUES}

In this work, we studied the effect of weak roentgen irradiation on the absorption and ultrasound velocity in $\mathrm{LiF}$ single crystals with a residual deformation of $0.65 \%$ at a frequency of $7.5 \mathrm{MHz}$ at a temperature of $300 \mathrm{~K}$.

In the experiments we used samples with a size of $17 \times 17 \times 27 \mathrm{~mm}$ and impurity content of $10^{-4} \mathrm{wt}$. $\%$, which were obtained by gouging along the cleavage planes $<100>$.

The ultrasound attenuation was measured by superimposing a calibrated exponent on the reflected echosignals, and the pulse interference method and the selector method [2] implemented on the equipment [20-27] were used to measure the velocity.

To carry out precision acoustic measurements, the samples under study, in accordance with the recommendations [20-27], were subjected to fine chemical polishing after gouging, so that the non-parallelism of their working edges was $\pm 1 \mu \mathrm{m} / \mathrm{cm}$, which was controlled using an IKV-type optimeter. An additional estimate of the degree of non-parallelism in the "piezo-quartzgluing - sample" system could also be obtained in the process of superimposing a calibrated exponent on a series of reflected pulses observed on the oscilloscope screen. To remove internal stresses that could arise during mechanical processing of the samples, they were annealed for $\sim 12 \mathrm{~h}$ in an MP-2UM muffle furnace at a temperature of $\sim 0.8 \mathrm{~T}_{\mathrm{m}}$ (where $\mathrm{T}_{\mathrm{m}}$ is the melting tem- 
perature), followed by slow cooling to room temperature.

In order to introduce "easily mobile" dislocations into the crystal, it was preliminarily deformed to obtain a residual deformation $\varepsilon=0.65 \%$. Deformation of the samples was carried out by compression on an Instrontype tensile testing machine at a rate of $\sim 10^{-5} \mathrm{~s}^{-1}$. In this deformation mode, slip bands do not appear, and the etching pits uniformly cover the etched surface of the crystal [20-27], which makes it possible to accurately determine the dislocation density in the crystals. The technology for separating the dislocation component from the total absorption was the same as in [20-27].

Irradiation of the investigated LiF crystals was carried out on a standard X-ray unit of the URS-55 type, which provided a radiation dose rate of $\sim 0.11 \mathrm{R} / \mathrm{s}$ at the location of the crystal under study. To avoid the appearance in the sample of possible inhomogeneities caused by the action of internal mechanical stresses [1], each of the 4 side faces parallel to the long axis of the crystal was irradiated alternately for $20 \mathrm{~min}$, which corresponded to a total dose of $1057 \mathrm{R}$.

\section{RESULTS AND DISCUSSION}

Fig. 1 shows the results of a study of the dependence of the dislocation absorption $\alpha$ and the velocity $v$ on the time of irradiation with $\mathrm{X}$-rays for LiF samples with residual deformation $\varepsilon=0.65 \%$.

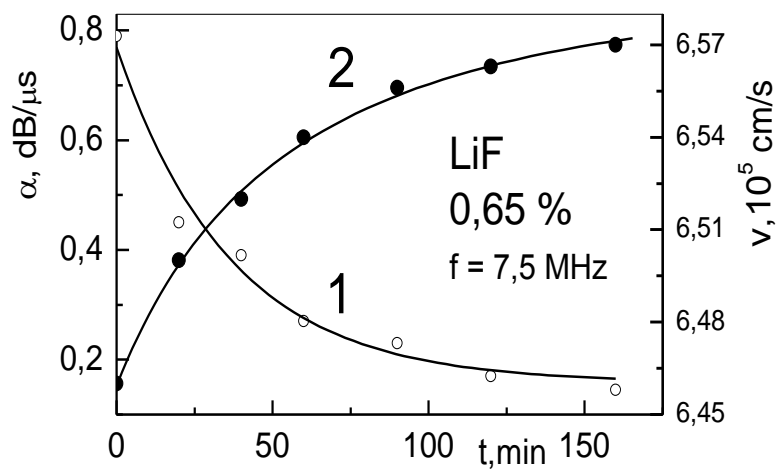

Fig. 1. Dependence of dislocation absorption (1) and velocity (2) of ultrasound on the irradiation time

for deformed $(0.65 \%)$ LiF crystals at $T=300 \mathrm{~K}$

It can see that after the first 20 min of irradiation, the ultrasound attenuation in the sample decreased by $0.34 \mathrm{~dB} / \mu \mathrm{s}$, and in the remaining measurement time, its value decreased by another $0.3 \mathrm{~dB} / \mu \mathrm{s}$. Experimental data obtained on the same sample when measuring the ultrasound velocity, which are also shown in Fig. 1, turned out to be quite expected. It can be seen from the above figure that with an increase in the radiation dose, the effect of an increase in the propagation velocity of the ultrasonic wave in the crystal is significantly manifested.

It should be noted that a similar effect of changing the acoustic characteristics was previously observed [2] upon irradiation of $\mathrm{NaCl}$ crystals. According to the authors of [2], this is due to a decrease in the effective length of the dislocation loop $L$ due to its fixation by radiation defects, the number of which is added during the irradiation time to a certain dislocation loop with the initial length $L_{0}$.

Using the data on $v$ and $\alpha$, it is possible to calculate the parameters of the dislocation structure $\Lambda$ and $L$, according to the formulas [2] for low frequencies:

$$
\begin{gathered}
\Lambda=8,6810^{-6}\left(\frac{\pi^{4} B}{\Omega G b^{2}}\right) f^{2}\left[\frac{\left(\Delta v / v_{0}\right)^{2}}{\alpha}\right], \\
L=\frac{1}{2 v}\left[\frac{10^{6}}{8.68} \frac{C}{B} \frac{\alpha}{\Delta v / v_{0}}\right] 1 / 2,
\end{gathered}
$$

where $B$ is the viscosity coefficient calculated from the descending branch of the damped dislocation resonance; $\Delta v=v_{0}-v\left(v_{0}\right.$ is the velocity in the initial annealed sample, measured at a frequency of $217.5 \mathrm{MHz}$ ); $\Omega$ is the orientation factor; $C$ is the linear tension of the dislocation; $G$ - shear modulus; $b$ is the magnitude of the Burgers vector; $f$ is the operating frequency of the ultrasonic wave.

Substituting in formulas (1), (2) the values $\Omega=0.311 ; G=3.533 \cdot 10^{10} \mathrm{~Pa} ; b=2.85 \cdot 10^{-10} \mathrm{~m}$; $f=7.5 \cdot 10^{6} \mathrm{~Hz} ; C=25.1 \cdot 10^{-10} \mathrm{~Pa} \cdot \mathrm{m}^{2}$ and data on the parameter $B=3.7 \cdot 10^{-5} \mathrm{~Pa} \cdot \mathrm{s}$, obtained by us earlier in works [22, 24], as well as data on $\Delta v / v_{0}$ and $\alpha$ (see Fig. 1) (taking into account $v_{0}=6.533 \cdot 10^{3} \mathrm{~m} / \mathrm{s}$ ), we plotted the dependences of the parameters of the dislocation structure $L$ and $\Lambda$ on the irradiation time, shown in Fig. 2.

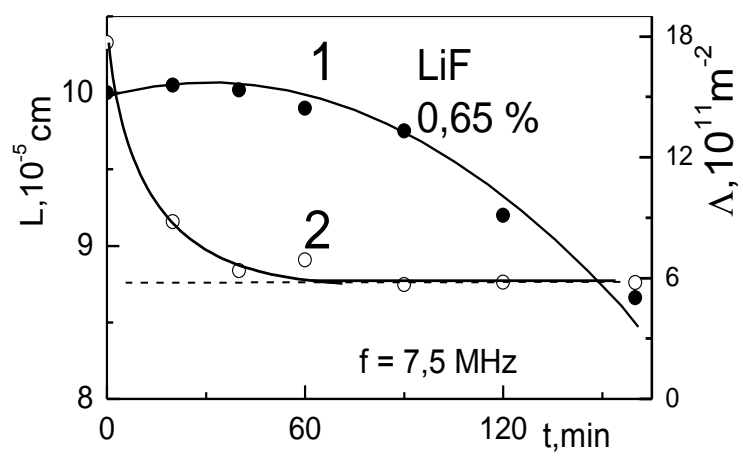

Fig. 2. Dependence of the average effective length of a dislocation segment (1) and dislocation density (2) on the irradiation time for LiF crystals with a $0.65 \%$ residual deformation at $T=300 \mathrm{~K}$

It can be seen that the value of $\Lambda$ value after $40 \mathrm{~min}$ of irradiation is no longer dependent on the irradiation time, and a small deviation at the initial stage of irradiation may be due to the fact that the initial deformation of $0.65 \%$ lowers the value of the resonance frequency $f_{m}$, due to which the condition $f l f_{m}$ « 1 , laid down in the theory [2] may not be performed strictly enough to make possible the simplifications obtained by them in the derivation of relations (1) and (2).

By measuring the frequency dependences of the dislocation resonance on the same LiF crystals, in paper [25] it was found that the resonance maximum lay at a frequency of $14 \mathrm{MHz}$ before irradiation, and after 20 and $40 \mathrm{~min}$ of irradiation it moved to the positions of 25 and $40 \mathrm{MHz}$, respectively. 
At the same time, the operating frequency of $7.5 \mathrm{MHz}$, at which the values of $\alpha$ and $\Delta v / v_{0}$ were measured in this work, was already in the linear section of the ascending branch of the frequency profile [3], where the condition $f / f_{m}$ « 1 is fulfilled.

The authors of [2] introduced a special parameter to explain this anomaly in the behavior of $\Lambda$ with irradiation:

$$
R=\frac{\Delta v / v_{o}}{\alpha^{1 / 2}}
$$

From formulas (1) and (2) it follows that this parameter at a given frequency should remain constant, as long as $\Lambda$ is unchanged, and the model [2] itself assumes that during irradiation $\Lambda$ is unchanged but point defects are created that can fix the dislocations.

Due to the change in velocity with irradiation (see Fig. 1), in the early stages of irradiation, the parameter $R$ changes, which, in turn, sets the tone for the change in characteristic $\Lambda$ with irradiation.

The variation of the parameter $R$ with irradiation is shown in Fig. 3. A similar curve for $\mathrm{NaCl}$ crystals is given in review [2].

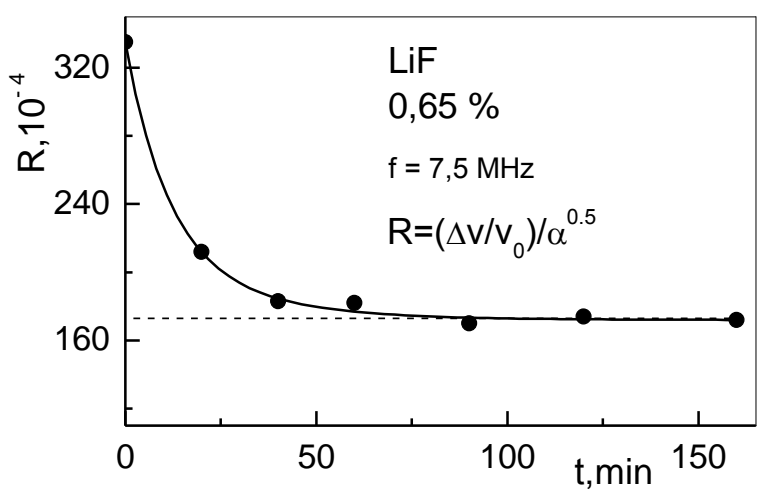

Fig. 3. Dependence of the parameter $R$ on the irradiation time in LiF crystals with a residual deformation of $0.65 \%$ at $T=300 \mathrm{~K}$

As for the behavior of the parameter $L$ with irradiation, it can be seen that, practically in the entire investigated interval, the average effective length of the dislocation segment decreases as the irradiation dose increases. The insignificant non-monotonicity of the curve at the early stages of irradiation is explained, as in the case of $\Lambda$, by the behavior of the parameter $R$. Comparing the absolute values of $L$ obtained in this work with the estimates of $L_{\mathrm{e}}$ from $3 \cdot 10^{-5} \mathrm{~cm}$ to $8 \cdot 10^{-5} \mathrm{~cm}$, found from the high-frequency branch of the dislocation resonance [32], and $\Lambda$, calculated by us above, with the results of determining this parameter by the selective etching method $\Lambda_{e}=1.74 \cdot 10^{10} \mathrm{~m}^{-2}$, a noticeable discrepancy in the values of these parameters (approximately two times more for $L$ and more than an order of magnitude for $\Lambda$ ) was revealed.

Such a difference, according to [28], is due to the impossibility of describing, within the framework of the dislocation theory [3], acoustic measurements carried out in a wide frequency range using a unified damping mechanism.
The results obtained can be useful in experiments where the effect of ionizing radiation on the radiation resistance of structural and modeling materials is studied [29-31].

\section{CONCLUSIONS}

1. The effect of X-ray irradiation in the dose range $0 . . .1057 \mathrm{R}$ on dislocation absorption $\alpha$ and ultrasound velocity $v$ in $\mathrm{LiF}$ single crystals deformed to $0.65 \%$, measured at a frequency of $7.5 \mathrm{MHz}$ at room temperature, has been studied. A noticeable decrease in the attenuation and an increase in the velocity were found in the early stages of irradiation. This behavior of acoustic characteristics with an increase in the radiation dose is associated with a decrease in the mobility of dislocations due to their pinning by point radiation defects.

2. On the basis of the obtained experimental data and relations for low-frequency measurements of the Granato-Lukke theory, in this work, we determined the absolute value of the structural characteristics of the crystal $L$ and $\Lambda$ and their behavior under conditions of a change in the sample irradiation dose.

3. The analysis of the behavior of the parameters $L$ and $\Lambda$ with irradiation in the entire investigated range of irradiation is carried out, the detected anomalies are explained within the framework of the Granato-Lukke theory. The calculated characteristics $L$ and $\Lambda$ are compared with the previously obtained results for the highfrequency branch of the damped dislocation resonance and using the selective etching method, and a noticeable discrepancy in the values of these parameters is revealed, which is explained by the impossibility [28] of describing acoustic measurements in a wide frequency range within the dislocation theory using a single damping mechanism.

\section{REFERENCES}

1. A.A. Botaki, A.A. Vorobev, V.A. Ulyanov. Radiation physics of ionic crystals. M.: "Atomizdat", 1980, $208 \mathrm{p}$.

2. R. Truell, Ch. Elbaum, B. Chik. Ultrasound methods in solid state physics. M.: "Mir", 1972, 307 p.

3. A. Granato, K. Lücke. String model of dislocation and dislocation ultrasound absorption // Physical acoustic. (Part A). M.: "Mir", 1969, v. 4, p. 261-321.

4. R.M. Stern, A. Granato. Damped dislocation resonance in copper // Internal friction and defects in metals. M.: "Metallurgiya", 1965, p. 149-191.

5. S.P. Nikanorov, B.K. Kardashov. Elasticity and Dislocation Inelasticity of Crystals. M.: "Nauka", 1985, $256 \mathrm{p}$.

6. V.S. Postnikov. Inernal friction in metals. M.: "Metallurgiya", 1969, 330 p.

7. V.I. Startsev, V.Ya. Ilyichev, V.V. Pustovalov. Plasticity and strength of metals and alloys at low temperatures. M.: "Metallurgiya", 1975, 328 c.

8. M.A. Krishtal, S.A. Golovin. Internal friction and metal structure. M.: "Metallurgiya", 1976, 375 p.

9. A. Smakula. Uber Erregung und Entfarbung lichtelektrisch leitender Alkalihalogenide // Z. Physik. 1930, N 9-10 (59), p. 603-614. 
10. A. Smakula, P. Avakiant. Color centers in cesium halide single crystals // Phys. Rev. 1960, N 6, p. 2007-2014.

11. D.L. Dexter. Absorption of light by atoms in solids // Phys. Rev. 1956, N 101, p. 48-55.

12. V.M. Lisitzyn. Radiation solid state physics. Tomsk: "Izdatelstvo Tomskogo Politekhnicheskogo Universiteta", 2008, 172 p. (in Russian).

13. I.A. Parfianovich, E.E. Penzina. Electronic color centers in ionic crystals. Irkutsk: "East-Siberian publishing house", 1977, $208 \mathrm{p}$.

14. G.A. Petchenko, S.S. Ovchinnikov. Effect of the preliminary deformation and irradiation on the optical absorption in LiF crystals // Problems of Atomic Science and Technology. Series "Physics of Radiation Effect and Radiation Materials Science”. 2014, N 2(90), p. 2933.

15. G.A. Petchenko, A.M. Petchenko. Dependence of electronic color center concentration on the state of irradiated LiF crystal dislocation structure // Problems of Atomic Science and Technology. Series "Physics of Radiation Effect and Radiation Materials Science". 2015, N 2(96), p. 25-28.

16. M.V. Galustashvili, M.G. Abramishvili, D.G. Driaev, V.G. Kvachadze. Effect of magnetic field on the radiation hardening LiF crystals // FTT. 2011, N 53(7), p. 1340-1342.

17. T. Klempt, S. Schweiser, K. Schwartz, et al. Magnetic resonance unvestigation of the dynamics of $F$ centers in LiF // Solid State Communications. 2001, N 119, p. 453-458.

18. A.V. Granato, J. de Clerk, R. Truell. Dispersion of elastic waves in sodium chloride // Phys. Rev. 1957, v. 108, N 3, p. 895-896.

19. L.P. Blinov, A.E. Kolesnikov, L.B. Langans. Acoustic measurements. M.: "Izd. Standartov", 1971, $271 \mathrm{p}$.

20. O.M. Petchenko, G.O. Petchenko. Phonon drag of dislocations in $\mathrm{KCl}$ crystals with various dislocation structure states // Ukrainian journal of physics. 2010, v. 55, N 6, p. 716-721.

21. A.M. Petchenko, V.I. Mozgovoi, A.F. Sirenko, A.A. Urusovskaya. Return of attenuation and ultrasound speed during stress relaxation in sodium chloride single crystals // FTT. 1989, v. 31, N 6, p. 127-130.

22. G.O. Petchenko, O.M. Petchenko. Research of the elastic wave velocity dispersion in X-ray-irradiated LiF crystals // Ukrainian journal of physics. 2013, v. 58, N 10, p. 974-979.

23. A.A. Urusovskaya, A.M. Petchenko, V.I. Mozgovoi. The influence of strain rate on stress relaxation // Phys. stat. sol. (a). 1991, v. 125, N 1, p. 155-160.

24. G.A. Petchenko, A.M. Petchenko. The study of the dislocation resonance in LiF crystals under the influence of the lowdose X-irradiation // Functional Materials. 2010, v. 17, N 4, p. 421-424.

25. G.A. Petchenko. Research of the preliminary deformation and irradiation effect on the viscous damping of dislocation in LiF crystals // Functional Materials. 2013, v. 20, N 3, p. 315-320.

26. A.M. Petchenko, G.A. Petchenko. Features of resonance absorption of longitudinal ultrasound in strained crystals $\mathrm{KBr}$ at temperature variations // Functional Materials. 2007, v. 14, N 4, p. 475-479.

27. A.M. Petchenko, D.L. Stroilova, A.A. Urusovskaya. Temperature dependence of the coefficient of damping of dislocations in single CsJ crystals // FTT. 1988 , v. 30, N 11, p. 3455-3460.

28. V. Naundorf, K. Lücke. Mechanisms of Internal Friction in Solids. M.: "Nauka", 1976, 91 p.

29. V.N. Voyevodin and I.M. Neklyudov. Evolution of the Structural-Phase State and Radiation Resistance of Structural Materials. Kiev: "Naukova dumka", 2006.

30. G.D. Tolstolutskaya, V.V. Ruzhytskyi, V.N. Voyevodin, I.E. Kopanets, S.A. Karpov, A.V. Nikitin. The role of radiation damage on retention and temperature intervals of helium and hydrogen detrapping in structural materials // J. Nucl. Mater. 2013, v. 442, p. S710S714.

31. I.M. Nekludov, A.K. Malik, A.A. Parkhomenko, A.V. Rudnitskiy. Ionization mechanisms of radiationinduced defects' generation in LiF crystals irradiated with high-energy electrons. // Problems of Atomic Science and Technology. 2009, N 2(93), p. 52-56.

\title{
ИЗУЧЕНИЕ ВЛИЯНИЯ РЕНТГЕНОВСКОГО ОБЛУЧЕНИЯ НА ДИСЛОКАЦИОННЫЕ ХАРАКТЕРИСТИКИ В КРИСТАЛЛАХ LiF
}

\author{
А.М. Петченко, Г.А. Петченко, С.Н. Бойко, А.С. Литвиненко
}

Акустическим импульсным эхо-методом на частоте 7,5 МГц исследованы зависимости поглощения $\alpha$ и скорости ультразвука в монокристаллах $\mathrm{LiF}$ с остаточной деформацией $\varepsilon=0,65 \%$ при 300 К в интервале доз облучения $0 \ldots 1057$ Р. На основе результатов измерений акустических характеристик определены абсолютные значения параметров дислокационной структуры $L, A$ и их зависимости от времени облучения. Проведено сравнение рассчитанных характеристик с полученными ранее результатами для высокочастотной ветви задемпфированного дислокационного резонанса и с результатами, полученными методом избирательного травления. Выявленное заметное расхождение в значениях этих параметров объясняется невозможностью описания единым механизмом затухания акустических измерений, проводимых в широком диапазоне частот. 


\section{ВИВЧЕННЯ ВПЛИВУ РЕНТГЕНІВСЬКОГО ОПРОМІНЕННЯ НА ДИСЛОКАЦЙНІ ХАРАКТЕРИСТИКИ В КРИСТАЛАХ LiF}

О.М. Петченко, Г.О. Петченко, С.М. Бойко, А.С. Литвиненко

Акустичним імпульсним ехо-методом на частоті 7,5 МГц досліджено залежності поглинання $\alpha$ i швидкості ультразвуку в монокристалах $\mathrm{LiF}$ із залишковою деформацією $\varepsilon=0,65 \%$ при $T=300 \mathrm{~K}$ в інтервалі доз опромінення 0..1055 Р. На основі результатів вимірювань акустичних характеристик визначено абсолютні значення параметрів дислокаційної структури $L, \Lambda$ і їх залежностей від часу опромінення. Проведено порівняння розрахованих характеристик із отриманими раніше результатами для високочастотної гілки задемпфованого дислокаційного резонансу і з результатами, які отримані методом вибіркового травлення. Виявлена помітна розбіжність у значеннях цих параметрів пояснюється неможливістю описання єдиним механізмом затухання акустичних вимірювань, що проводяться в широкому діапазоні частот. 